\title{
IPOMOEA BATATAS NO BRASIL
}

\section{IPOMOEA BATATAS IN BRAZIL}

\author{
Taynara Cristini Daron ${ }^{1 *}$, Ana Maria Tomimatsu ${ }^{1}$, Ana Paula Silva Mello ${ }^{1}$, Bianca \\ Aliatti Dos Santos ${ }^{1}$, Daniela Miotto Bernardi² \\ ${ }^{1}$ Nutricionistas, Centro Universitário Fundação Assis Gurgacz - FAG. ${ }^{2}$ Nutricionista professora de \\ Nutrição. Centro Universitário Fundação Assis Gurgacz - FAG. \\ * Autor correspondente: taynaradaron@gmail.com https://orcid.org/0000-0001-8160-1497
}

DOI: $10.35984 / f j h . v 2 i 1.145$

RESUMO

Batata Doce é uma hortaliça tuberosa original do México, cultivar rústico em nosso país predominante na região Sul e Nordeste, fácil de cultivar, pois se adapta em climas tropicais, apresenta baixa tolerância a geada e exige temperaturas relativamente altas. Fundamental na alimentação humana e animal, sendo muito usada para indivíduos que possuem restrições, pois são consideradas alimentos fontes de vitaminas e minerais para melhor qualidade de vida sua característica destaca-se por macronutrientes e rica em fibras e minerais. Muito ligada a alimentação funcional e desenvolvimento através de biofortificados de produtos inovadores no mercado como farinhas, bolos, cokkies e até mesmo sucos.

Palavras chaves: Batata-doce, Ipomoea batatas, Nutrição, Compostos fenólicos

\begin{abstract}
Sweet Potato is a tuberous vegetable original from Mexico, a rustic cultivar in our contry, predominant in South and Northeast regions, easy to grow because it adapts to tropical climates, hás low frost tolerance and requires relatively high temperatures. Fundamental in human and animal feeding, it is very used by individuals Who have restrictions, because it is considered as source of vitamins and minerals to better quality of life, its characteristic stands out for having macronutrients and being rich in fibers and minerals. Very linked to funcional food and development through biofortified innovative protucts in the market like flours, cakes, cookies and aven juices.
\end{abstract}

Keywords: Sweet Potato, Ipomoea batatas, Nutrition, Phenolic compounds

\section{INTRODUÇÃO}

A batata doce (Ipomoea batatas) é uma hortaliça tuberosa(SILVA. et al, 1995), pertencente da família Convolvulaceae, sendo a única hexaplóide $(2 \mathrm{n}=6 \mathrm{x}=90)$ (FABRI,2009). Acredita-se que essa cultivar seja originaria da faixa entre o México e o Norte da America do Sul (SILVA., et al., 2015). Caracteriza-se por ser uma cultura rústica de fácil adaptação com relação ao meio que esta inserida (MELO, et al., 2012), sua rusticidade faz com que seu cultivo seja fácil, exigindo poucos investimentos para a implementação da lavoura (NORONHA, 2018), o que torna a cultivar de importância econômica (SILVA., et al., 2015).

As regiões Sul e Nordeste do país, são as que possuem maior área de cultivo de batata-doce e isso só é possível devido a fácil adaptação da cultivar, tendo em vista que ambas as regiões apresentam micro-climas distintos (MELO., et al., 2011).A cultivar possui ampla adaptação climática, entretanto adapta-se melhor a climas tropicais (MELO., et al., 2011),todavia a batata-doce não possui tolerância a geadas e exige temperaturas relativamente altas (SILVA., et al., 1995). 
A principal finalidade da batata doce é a alimentação humana e / ou animal (CASTRO., et al.,2018) tendo grande importância na alimentação humana, principalmente indivíduos que possuem restrição alimentar (MELO., et al., 2011). Toda a planta pode ser consumida, tendo a forma de preparo variada (SILVA., et al, 1995). O consumo da batata doce tem relação direta com a saúde e a qualidade de vida humana (CARVALHO., et al,2008).

A composição da batata-doce tem como destaque o carboidrato como macronutriente, tendo proteína como a segunda fonte de maior valor, é rica em fibras e micronutrientes, tais como, fósforo, potássio, vitamina $\mathrm{C}$ e niacina (TACO, 2011).

Cultivares de batata doce biofortificadas já são uma realidade no Brasil. A biofortificação tem como finalidade o desenvolvimento de produtos agrícolas com quantidade de nutrientes (MELLO., et al.,2011).

Com isso tem-se como objetivo realizar uma revisão bibliográfica sistemática sobre a cultivar da batata-doce.

\section{METODOLOGIA}

Foi realizada a revisão bibliográfica sobre o tema cultivar da batata doce no Brasil, foram utilizadas revistas cientificas acadêmicas disponíveis on-line, reunindo e comparando dados encontrados nas fontes de consulta e listando os principais fatores. Foram usadas como base de dados para a pesquisa plataforma de dados científicosScielo, PubmedeMedline. Para a busca foram utilizadas palavras chaves como: 'Batata Doce', 'Ipomoea', 'Biofortificada', 'Yacon', 'Raiz Tuberosa'. Foram encontrados 1.426 artigos como resultado de busca, foram usados 36 para a elaboração do artigo de revisão.

\section{ASPECTOS AGRONÔMICOS}

A batata-doce (Ipomoea batatas) é classificada como um tubérculo (SEVERO., et al., 2018), é uma dicotiledônea (SILVA., et al., 2008) pertencente da família Convolvulaceae, sendo o único membro hexaplóide $(2 n=6 x=90)$, tendo grande variedade por apresentar alto nível de ploidia( SILVA, et al., 2015). Caracteriza-se por ser uma cultura perene e de tuberização continua, quando cultivada em local favorável (ERPEN et al., 2013).

Destacam-se como características morfológicas o caule herbáceo de habito prostrado, ramificações variáveis, folhas largas e com formatos variáveis, pecíolo longo, flores hermafroditas porem de fecundação cruzada (SILVA et al., 2008).

A Ipomoea batatas pode ser cultivada de latitudes que vão de $42^{\circ} \mathrm{N}$ até $35^{\circ} \mathrm{S}$ e altitudes que variam do nível do mar até 3000 metros acima do nível do mar (MELO et al., 2011). O local de cultivo da batata-doce possui relação direta com a escolha da cultivar, pois o mesmo deve possibilitar que suas exigências agronômicas sejam supridas (SOUZA et al., 1989).

Possui capacidade de desenvolver-se e produzir bem em qualquer tipo de solo, porem, solos leves, soltos, estruturados e com fertilidade de media à alta, são considerados ideias para a cultivar (SILVA et al., 1995), o solo deve estar isento da presença de alumínio tóxico, possuir pH ligeiramente acido (SILVA et al., 2008), considerando que a cultura desenvolve-se bem na faixa de $\mathrm{pH}$ de 4.5 à 7.5 e tem como níveis de pH ótimos entre 5.6 à 6.5(SOUZA et al., 1989),e possuir alta capacidade de drenagem (SILVA et al., 2008), solos que não possuem boa drenagem 
retardam a formação das raízes tuberosas, devido a aeração deficiente (SOUZA et al., 1989).

Por tratar-se de uma planta tropical a mesma exige que a temperatura média, do local de cultivo, seja superior $24^{\circ} \mathrm{C}$, para apresentar um adequado desenvolvimento vegetativo (SILVA et al., 1995). A temperatura é determinante para a formação e desenvolvimento das raízes tuberosas (ERPEN et al., 2013), regiões mais quentes tendem a resultar em raízes com teor de açúcar elevado e teor de amido reduzido em sua composição (SILVA et al., 1995). A temperatura também tem relação direta com a produtividade de matéria seca, que aumenta com a elevação da temperatura do solo, e o ciclo da cultura, que e reduzido quando há elevados índices de temperatura e luminosidade (SOUZA et al., 1989).

Com relação ao regime pluvial, a cultivar deve ser implantada em locais que possui a pluviosidade anual média de 750 a 1000 mm (SILVA et al., 2008) e / ou locais que durante o ciclo da cultura ofertem entre 500 a $600 \mathrm{~mm}$ de chuva (SILVA et al., 1995; SILVA et al., 2008).

A época de plantio apresenta variabilidade, em função das condições do local em que o mesmo será realizado (SOUZA et al., 1989; SILVA et al., 1995) no Brasil as áreas de cultivo de batata-doce são manejadas por meio de preparo convencional, entre tanto recomenda-se que o mesmo seja de manejo conservacionista(Rós et al., 2013). A qualidade fitossanitária da área de cultivo de batata-doce tem relação direta com o material utilizado para a propagação da mesma (GUERRA et al., 2006), é de fundamental importância o uso de materiais de alta sanidade para obter-se sucesso no cultivo (NORONHA et al., 2018).

Com relação ao plantio, ele pode ser realizado de forma manual ou mecanizado (SILVA et al., 2008), as ramas ou mudas devem ser plantadas no ponto mais alto das leiras e o espaçamento entre plantas varia em função dos diferentes hábitos de crescimento de cada cultivar (SILVA et al., 1995; SOUZA et al., 1989), os espaçamentos mais utilizados estão na faixa de 80 a $100 \mathrm{~cm}$ entre leiras e de 25 a 40 cm entre plantas(SILVA et al., 1995). Os sulcos, onde as ramas serão inseridas devem permitir o contato direto da base da rama com o solo, deve-se acomodar o solo de forma que metade do comprimento da rama fique enterrada (SILVAet al., 2008), as ramas escolhidas para serem plantadas devem ter de oito a dez entrenós (SILVA et al., 1995). Quando cultivada em regiões de clima subtropical, a batata-doceapresenta maior produtividade, quando seu plantio é realizado no final do inverno (ERPEN et al., 2013).

A nutrição e adubação do solo devem ser pensadas com base nos elementos extraídos do mesmo, assim de conservar sua capacidade produtiva (SILVA et al., 2008). Em ordem decrescente, as exigências minerais da cultura da batata-doce são: potássio, nitrogênio, fósforo, cálcio e magnésio (SOUZA et al., 1989; SILVA et al., 1995). A aplicação de matéria orgânica no solo promove arejamento e afrouxamento do mesmo, causando efeitos benéficos no desenvolvimento das raízes da cultivar, alem de liberar, de forma equilibrada, minerais resultantes de sua decomposição (SILVA et al., 2008).

Tratos culturais são definidos como as principais exigências de uma cultura, para que a mesma possa expressar seu máximo potencial produtivo (ALVES et al., 2004). Os principais tratos culturais da cultivar da batata-doce são a amontoa, (SILVA et al., 2008), reposição de falha e controle de plantas daninhas (SOUZA et al., 1989).

A amontoa compreende na reforma das leiras, deve ser realizada mecanicamente e tem a finalidade de tornar o solo menos resistente e / ou vedar 
rachaduras do solo que são resultantes do crescimento das raizes(SILVA et al., 2008). A reposição de falhas é necessária quando ocorre mais de 12 a $15 \%$ de falhas no plantio, deve ser realizadas até quinze dias após o plantio (SILVA et al., 1995). O controle de platas daninhas pode ser realizado com herbecidas regisgtrados para a cultura ou atraves da capina, sendo o ponto critico de competiçao entre a cultivar e a daninha aproximadamente 45 dias após o plantio(SILVA et al., 2008).

Literaturas especializadas da cultura da batata-doce relatam a ocorrência de fungos, vírus, nematóides(SOUZA et al., 1989; SILVA et al., 1995), micoplasmas e bactérias (SILVA et al., 1995). Consideram-se como as principais pragas da batatadoce a broca-da-raiz (Euscepespostfasciatus) e broca-das-hastes (Megastespusialis), pois estas são as que acarretam danos severos na cultura (SILVA et al., 2008).

A colheita da batata doce é definida pela finalidade da produção (SOUZA et al., 1989), para o consumo humano consideramos o tamanho e / ou peso das raízes, entre 110 e 165 dias após o plantio, a batata-doce está pronta para ser colhida (SILVA et al., 1995), com relaçao ao peso das raizes busca-se realizar a colheita, quando a mesma apresenta aproximadamente $300 \mathrm{~g}$, com isso considera-se que não haja um ponto especifico de colheita para essa cultivar (SILVA et al., 2008).Quando a finalidade da produção é a indústria e / ou alimentação animal, deve-se colher mais tarde, visando maior peso e produção de matéria seca (SOUZA et al., 1989). A colheita pode ser realizada de forma manual ou mecanizada e antes de realizar a mesma, deve-se cortar a ramagem das plantas (SILVA et al., 1995).

A classificação com relação a padronização, no Brasil, é determinada pelos principais mercados do pais, Rio de Janeiro e São Paulo (SILVA et al., 2008).

Na tabela 01, estão descritos os dados de adronização não oficial, com relação aos tamanhos das batatas-doces, segundo SILVA et al., 2008.

Tabela 01. Padronização não oficial, com relação aos tamanhos das batatas-doces, segundo SILVA et al., 2008.

\begin{tabular}{lll} 
& TIPO & \multicolumn{1}{c}{ PESO } \\
\hline Extra A & & $301 \mathrm{a} 400 \mathrm{~g}$ \\
Extra B & $201 \mathrm{a} 300 \mathrm{~g}$ \\
Especial & $151 \mathrm{a} 200 \mathrm{~g}$ \\
Diversos & 80 a $150 \mathrm{~g}$ ou maiores que $400 \mathrm{~g}$ \\
\hline
\end{tabular}

\section{COMPOSIÇÃO}

A batata-doce é um alimento popular e apreciado em todo o território brasileiro (SOUZA et al., 1989). Caracteriza-se por ser um alimento energético, apresenta aproximadamente $30 \%$ de matéria seca, sendo que em média $85 \%$ de sua composição é carboidrato, tendo como principal componente o amido (SILVA et al., 2008).

Tem-se como valores da composição centesimal da raiz, com relação a macro nutriente, proteína $1,26 \mathrm{~g}$, lipídios $0,13 \mathrm{~g}$ e carboidratos $28,2 \mathrm{~g}$, totalizando $118 \mathrm{Kcal}$ de energia por $100 \mathrm{~g}(\mathrm{TACO}, 2011)$. O valor nutricional pode ser alterado de acordo com a cultivar e o micro-clima ao qual a mesma está inserida (SILVA et al., 1995).

$\mathrm{Na}$ tabela 02 estão descritos os dados referentes a composição centesimal da batata-doce encontrados em diferentes tabelas nutricionais.

Quando compara-se os dados apresentados pelas tabelas, com relação aos macronutrientes, encontra-se uma discrepância entre os valores apresentados, para 
proteína temos uma variável de $\pm 0,31 \mathrm{~g}$, para carboidrato os valores apresentam variável de $\pm 10,48 \mathrm{~g}$ e por sua vez, os lipídeos apresentam variável de $\pm 0,05 \mathrm{~g}$.

Tabela 02. Composição centesimal de batata-doce em diferentes tabelas

\begin{tabular}{lccc}
\hline NUTRIENTE & TACO* & IBGE** & USDA $^{\star * *}$ \\
\hline Proteína & $1,26 \mathrm{~g}$ & $1,37 \mathrm{~g}$ & $1,57 \mathrm{~g}$ \\
Carboidrato & $28,20 \mathrm{~g}$ & $17,72 \mathrm{~g}$ & $20,12 \mathrm{~g}$ \\
Lipídeo & $0,13 \mathrm{~g}$ & $0,14 \mathrm{~g}$ & $0,05 \mathrm{~g}$ \\
Cálcio & $21,11 \mathrm{mg}$ & $27 \mathrm{mg}$ & $30 \mathrm{mg}$ \\
Ferro & $0,39 \mathrm{mg}$ & $0,72 \mathrm{mg}$ & $0,61 \mathrm{mg}$ \\
Fibra alimentar & $2,57 \mathrm{~g}$ & $2,5 \mathrm{~g}$ & $3 \mathrm{~g}$ \\
Fósforo (P) & $36,46 \mathrm{mg}$ & $32 \mathrm{mg}$ & $47 \mathrm{mg}$ \\
G. Poli-insaturada & - & $0,06 \mathrm{~g}$ & $0,01 \mathrm{~g}$ \\
G. Saturada & - & $0,03 \mathrm{~g}$ & $0,02 \mathrm{~g}$ \\
Magnésio & $16,89 \mathrm{mg}$ & $18 \mathrm{mg}$ & $25 \mathrm{mg}$ \\
Manganês & $0,18 \mathrm{mg}$ & $0,27 \mathrm{mg}$ & $0,26 \mathrm{mg}$ \\
Potássio & $340,2 \mathrm{mg}$ & $230 \mathrm{mg}$ & $337 \mathrm{mg}$ \\
Selênio & - & $0,2 \mathrm{mcg}$ & $0,6 \mathrm{mcg}$ \\
Sódio & $8,77 \mathrm{mg}$ & $27 \mathrm{mg}$ & $55 \mathrm{mg}$ \\
Vitamina B1 (Tiamina) & $0,06 \mathrm{mg}$ & $0,06 \mathrm{mg}$ & $0,08 \mathrm{mg}$ \\
Vitamina B2 & - & $0,05 \mathrm{mg}$ & $0,06 \mathrm{mg}$ \\
(Riboflavina) & - & $0,54 \mathrm{mg}$ & $0,56 \mathrm{mg}$ \\
Vitamina B3 (Niacina) & $0,1 \mathrm{mg}$ & $0,17 \mathrm{mg}$ & $0,21 \mathrm{mg}$ \\
Vitamina B6 (Piridoxina) & - & $6 \mathrm{mcg}$ & $11 \mathrm{mcg}$ \\
Vitamina B9 (Ácido & & & \\
fólico) & $16,48 \mathrm{mg}$ & $12,8 \mathrm{mg}$ & $2,4 \mathrm{mg}$ \\
Vitamina C (Ácido & - & $0,94 \mathrm{mg}$ & $0,26 \mathrm{mg}$ \\
ascórbico) & $0,2 \mathrm{mg}$ & $0,2 \mathrm{mg}$ & $0,3 \mathrm{mg}$ \\
Vitamina E (Tocoferol) & &
\end{tabular}

*Tabela Brasileira de Composição de Alimentos.

**Instituto Brasileiro de Geografia e Estatística.

${ }^{* * *}$ United States Department of Agriculture.

Quando compara-se os dados apresentados pelas tabelas, com relação aos minerais, temos as seguintes variáveis, cálcio $\pm 8,89 \mathrm{mg}$, ferro $\pm 0,33 \mathrm{mg}$, fósforo \pm $10,54 \mathrm{mg}$, magnésio $\pm 8,11 \mathrm{mg}$, manganês $0,09 \mathrm{mg}$, potássio $110,2 \mathrm{mg}$, selênio 0,4 mcg, sódio 46,23 mg e zinco 0,1 mg por $100 \mathrm{~g}$ de batata-doce, a TACO não apresenta analise de selênio.

Com relação a fibra alimentar as tabelas apresentam dados que possuem variável de $\pm 0,5 \mathrm{~g}$, tendo como média $2,69 \mathrm{~g}$ de fibra por $100 \mathrm{~g}$ de batata-doce cozida.

Os valores das gorduras Poli-insaturada e saturadas apresentadas nas tabelas, possuem variáveis de $\pm 0,05 \mathrm{~g}$ e, $.01 \mathrm{~g}$ respectivamente.

Quando compara-se os dados apresentados pelas tabelas, com relação ao complexo B, temos as seguintes variáveis, vitamina B1 (Tiamina) $\pm 0,02 \mathrm{mg}$, vitamina B2 (Riboflavina) $\pm 0,01 \mathrm{mg}$, vitamina B3 (Niacina) $\pm 0,02 \mathrm{mg}$, vitamina B6 (Piridoxina) $\pm 0,04 \mathrm{mg}$ e vitamina B9 (Ácido fólico) $\pm 5 \mathrm{mcg}$.

Com relação as vitaminas e os valores apresentados pelas tabelas citadas a cima, temos que a vitamina C (Ácido ascórbico), apresenta uma grande variável, sendo ela $\pm 14,08 \mathrm{mg}$ e a vitamina $E$ (Tocoferol), por sua vez, apresenta variável de \pm $0,68 \mathrm{mg}$ por $100 \mathrm{~g}$ de batata-doce, a TACO não apresenta analise de Tocoferol.

A diferença entre os dados apresentados pelas tabelas de composição é notável, deve-se considerar que isso é resultado de diferentes protocolos de análises e diferentes amostras que foram analisadas. As amostras analisadas passaram por 
processos agrícolas diferentes e a resposta a interação com o meio também foram diferenciadas, todos esses pontos devem ser considerados quando analisamos os dados de composição de um alimento. Com relação a realidade brasileira, a TACO é a tabela que mais se aproxima dos valores reais encontrados em nosso pais, considerando que a mesma foi descrida com dados obtidos a partir de analises de alimentos produzidos no Brasil, toda via, se considerarmos a ampla extensão territorial e a grande variedade de cultivares de batata-doce, os dados descritos pela mesma representam somente uma pequena fração de todo o contexto nutricional que engloba 0 alimento descrito.

A batata-doce tem como componente majoritário de sua massa seca a fécula, variando entre 65 e $89 \%$ do valor total, é constituída de cadeias glicosídicas que constituem a amilose e a amilopectina(LEITE, 2017). Com relação a matéria seca apresenta-se teor elevado quando comparado a batata (SILVA et al., 2008).

Não á relatos de análise centesimal da batata doce fortificada, porem existem estudos que mostram os valores da analise centesimal da composição, valor energético e teor de carotenóides totais da fécula da batata-doce biofortificadas. Temse como valores da composição centesimal de fécula de batata-doce biofortificada, com relação a macronutriente $5,4 \mathrm{~g}$ de proteínas, 0,6 de lipídeos e 65,1g de carboidratos (NASCIMENTO et al., 2013).

$\mathrm{Na}$ tabela 03 estão descritos dados referentes as analises centesimais de fécula de batata-doce biofortificada, segundo(NASCIMENTOet al., 2013).

Tabela 03. Analise centesimal de fécula de batata-doce biofortificada (NASCIMENTO et al., 2013)

\begin{tabular}{ll}
\hline Análises & Grama por $\mathbf{1 0 0} \mathbf{g}$ de fécula de batata doce \\
\hline Umidade & $7,05 \pm 0,16 \mathrm{~g}$ \\
Cinzas & $2,88 \pm 0,22 \mathrm{~g}$ \\
Proteínas & $5,48 \pm 0,41 \mathrm{~g}$ \\
Lipídeos & $0,60 \pm 0,12 \mathrm{~g}$ \\
Carboidratos & $65,18 \pm 1,47 \mathrm{~g}$ \\
Fibras & $18,81 \pm 2,38 \mathrm{~g}$ \\
VET* $(\mathrm{kcal})$ & $287,88 \mathrm{Kcal}$ \\
$\mathrm{CT}^{* *}$ & $18 \times 10$ \\
\hline
\end{tabular}

VET: Valor energético total.

CT: Carotenoides totais em base seca.

A recomendação diária para um ser humano sadio é que $90 \%$ alimentos ingeridos sejam na característica in natura, sendo dividido nas três refeições principais(MINISTÉRIO DA SAÚDE, 2014).Considerando as recomendações supracitadas, um indivíduo que tenha uma dieta de $2000 \mathrm{Kcal}$ deve ingerir entre de $225 \mathrm{~g}$ e $325 \mathrm{~g}$ de carboidrato, $33 \mathrm{~g}$ e $66 \mathrm{~g}$ de lipídios e entre $50 \mathrm{~g}$ e $75 \mathrm{~g}$ de proteína, portanto ao ingerir $100 \mathrm{~g}$ de batata doce de polpa amarela consome, respectivamente, $12,7 \%$ a $8,8 \%$ da sua recomendação de carboidrato.Os cereais, preferencialmente integrais, juntamente com as leguminosas e as frutas e verduras, devem fornecer de $45 \%$ a $65 \%$ VET do total, de energia diária da alimentação, gorduras de $15 \%$ a $30 \%$ do VET total e proteínas $10 \%$ a $15 \%$ (OMS, 2015).

$\mathrm{Na}$ tabela 04 estão descritos os dados referentes a composição centesimal da batata-doce comparado a outras raízes e tubérculos, segundo (SOUZA et al., 1989). 


\section{COMPOSTOS BIOATIVOS}

O conceito de alimentos funcionais teve origem no Japão na década de 80 (COSTA et al., 2016). Tem-se como definição de alimento funcional, aquele que apresenta, além dos nutrientes conhecidos, compostos que possam ter ação benéfica à saúde (PIMENTEL et al., 2005), com isso podemos considerar a batata-doce um alimento funcional.

Tabela 04. Valor nutritivo da batata-doce comparado com outras raízes e tubérculos. Dados por $100 \mathrm{~g}$ de peso fresco.

\begin{tabular}{|c|c|c|c|c|c|c|c|c|c|c|c|}
\hline 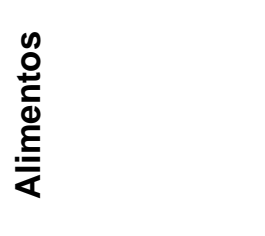 & 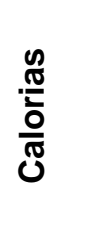 & 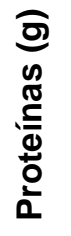 & 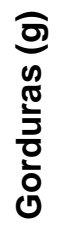 & 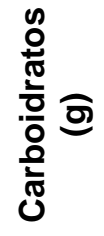 & 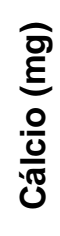 & 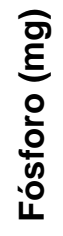 & 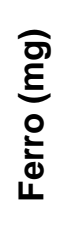 & 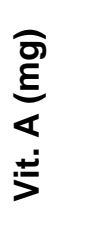 & 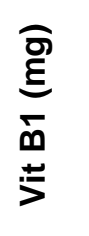 & 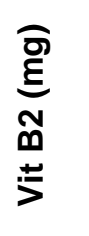 & 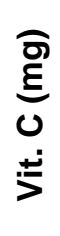 \\
\hline $\begin{array}{l}\text { Batata-doce } \\
\text { (polpa amarela) }\end{array}$ & 122.3 & 1.3 & 0.3 & 28.6 & 31 & 37 & 1.0 & 1815 & 0.11 & 0.04 & 31 \\
\hline $\begin{array}{l}\text { Batata-doce } \\
\text { (polpa branca) }\end{array}$ & 122.3 & 1.3 & 0.3 & 28.6 & 31 & 37 & 1.0 & 30 & 0.11 & 0.04 & 31 \\
\hline $\begin{array}{l}\text { Batata-doce } \\
\text { (polpa roxa) }\end{array}$ & 94.9 & 1.6 & 0.1 & 21.7 & 40 & 62 & 0.9 & 1050 & 0.9 & 0.02 & 23 \\
\hline $\begin{array}{l}\text { Batatinha, sem } \\
\text { casca }\end{array}$ & 79.7 & 18 & 0.1 & 17.9 & 6 & 40 & 0.9 & + & 0.09 & 0.03 & 16 \\
\hline Mandioca & 138.8 & 1.0 & 0.4 & 32.8 & 40 & 34 & 1.4 & 0 & 0.05 & 0.04 & 19 \\
\hline Cenoura & 42.4 & 0.8 & 0.4 & 8.9 & 34 & 26 & 0.9 & 3530 & 0.06 & 0.04 & 5 \\
\hline Cará ou Inhame & 107.0 & 2.0 & 0.2 & 24.3 & 14 & 43 & 1.3 & + & 0.13 & 0.02 & 3 \\
\hline Mandioquinha & 104.6 & 0.8 & 0.2 & 24.3 & 29 & 56 & 1.2 & 60 & 0.06 & 0.04 & 28 \\
\hline Nabo & 24.5 & 1.7 & 0.1 & 4.2 & 29 & 20 & 1.5 & 0 & 0.04 & 0.04 & 26 \\
\hline Rabanete & 24.5 & 0.9 & 0.1 & 5.0 & 26 & 30 & 1.2 & + & 0.03 & 0.03 & 28 \\
\hline
\end{tabular}

$(+)=$ Quantidade muito reduzida do nutriente

Segundo a tabela demostra a cima foi feito um comparativo, de diferentes legumes e raízes tuberosas para que possamos demonstrar o quanto temos de benefícios em batatas biofortificadas e do demais.

As substancias bioativas podem ser categorizadas quanto sua natureza química e molecular (COSTA et al., 2016). Os principais compostos bioativos presentes na batata-doce são as Antocianinas, Carotenóides e Flavonóide (LEITE, 2017).

As antocianinas apresentam estrutura básica C6-C3-C6 (VARGAS,2013) são substâncias de ocorrência natural abundantes no meio ambiente distribuídas nas plantas, flores, folhas elas conferem pigmento, sendo sintetizadas por rotas bioquímicas derivadas dos flavonóides (SCHIOZER, 2013). Possuem capacidade de absorver a luz no comprimento de onda visível do espectro eletromagnético, principalmente na região do vermelho, azul e amarelo, conferindo assim uma enorme variedade de cores dependendo de sua organização estrutural (VARGAS,2013). As antocianinas apresentam funções variadas podendo ser elas antioxidantes, função biológica, mecanismo de defesa e proteção à ação da luz. $\mathrm{Na}$ tabela 05 , as características básicas das antocianinas segundo Lopes et al., (2000), citada por Costa (2016).

As batatas-doces apresentam bom conteúdo de antocianinas, gerando interesse das indústrias de alimentos, visando à extração e estabilidade destes compostos, principalmente para aplicação na indústria de alimentos como corantes naturais. (SCHIOZER, 2013). 
Tabela 05.Flavonóides e suas características básicas (LOPES et al., 2000)

\begin{tabular}{llll}
\hline CLASSE & COLORAÇÃO & EXEMPLOS & FONTES \\
\hline Antocianinas & Azul, vermelha & Cianidina, Delfinidina & Frutas e flores \\
\hline
\end{tabular}

Fonte: Adaptação do quadro 2, apresentado por PIMENTEL et al., 2005.

Os carotenóides encontram-se na natureza, organizados principalmente como pigmentos naturais lipossolúveis (WONDRACEK el al., 2010), a estrutura dos carotenóides é devida à sua longa cadeia com duplas ligações conjugadas, sendo que alguns carotenóides podem ostentar estruturas cíclicas e atuar como precursor de vitamina A (LEITE, 2017). São responsáveis pelas cores amarelo, laranja e vermelho de vegetais, os quais atuam como antioxidantes nos vegetais e apresentam bioatividade no metabolismo humano, também é aplicado indústria como corante de ordem natural (WONDRACEK el al., 2010). Devido suas propriedades antioxidantes, os carotenóides possuem a capacidade de atuar como agente redutor de riscos de doenças cardiovasculares e cânceres (PIMENTEL et al., 2005).

A extração de carotenóides de batata-doce de polpa laranja e sua aplicação como corante natural em alimentos, principalmente quanto à obtenção de $\beta$-caroteno, apresentam valores entre 12,49 a $235,94 \mu \mathrm{g} / \mathrm{mL}$ de extrato(GINTING, 2013).

A batata-doce de coloração alaranjada é rica em beta-caroteno, possui alta quantidade em antocianinas, compostos fenólicos, fibras dietéticas, ácido ascórbico, ácido fólico e minerais (WOOLFE, 2008). O beta-caroteno é de extrema importância para prevenção de carcinogêneses, atuando no aumento das células imunológicas capazes de atuar sob células tumorais (LUCIA et al.,2016)

Os flavonóides englobam um grupo de compostos fenólicos distribuídos em plantas, principalmente nas frutas e vegetais evidenciados sob a variantes como flavonas, flavonóis, flavanonas, antocianinas, catequinas, isofravonas( LEITE, 2017). Flavonoides são metabólitos secundários sintetizados pelas plantas, compreendem um número importante de pigmentos naturais, possuem o mesmo núcleo flavona $\mathrm{C}_{15}$ $\left(\mathrm{C}_{6}-\mathrm{C}_{3}-\mathrm{C}-6\right)$,com dois anéis benzênicos ligados por meio de anel pirano contendo oxigênio(O) (BORGO, et al. 2016). São sintetizados pelas reações de substancias derivadas dos aminoácidos fenilalanina e ácido acético ( LEITE, 2017).

\section{BIOFORTIFICADOS}

Estima-se que 3 bilhões de pessoas no mundo sofrem de deficiência de micronutrientes e mais de 1.02 bilhões de pessoas não consomem alimentos suficientes para suprir suas necessidades calóricas diária (NUTTI et al., 2012). A suplementação de micronutrientes e o desenvolvimento de produtos biofortificados são estratégias para combater essa realidade de países em desenvolvimento (CURADO et al., 2010).

No Brasil a indicadores que a ingestão de ferro, cálcio, zinco, selênio estão a baixo do recomendado ou possuem baixa biodisponibilidade, medidas foram tomadas afim de fortificar do sal de cozinha com iodo, fluorestação da água (NUTTI et al., 2005).

A introdução de produtos agrícolas biofortificados de variedades melhoradas que apresentam maior índice de minerais e vitaminas vem como aliado das intervenções em nutrição e proporcionará uma maneira sustentável e de baixo custo para população com acesso limitado aos alimentos (Harvest Plus et al., 2006). O enriquecimento dos grãos com micronutrientes, além de favorecer a diminuição dos índices de deficiências nutricionais em humanos, aperfeiçoa o desempenho de 
genótipos biofortificados em solos com deficiência desses minerais (RISSIN et al., 1998).

Os biofortificados são produtos agrícolas que possuem melhor valor nutritivo quando comparado aos alimentos convencionais (MELO et al., 2011), apresentam um conteúdo elevado de vitaminas e minerais (NUTTI et al., 2012) tem como objetivo suprir as necessidades nutricionais dos seres humanos (MELO et al., 2011). Visa complementar a nutrição dos indivíduos de forma sustentável e com baixo custo, assim de atingir a população que tem acesso limitado aos sistemas formais de saúde e de mercado (NUTTI et al., 2012), entretanto a deficiência de infra-estrutura altamente funcional pode limitar o fornecimento desses alimentos a população (WATANABE et al., 2006).

Os produtos biofortificado que estão em desenvolvimento no Brasil são o arroz, feijão, trigo, mandioca (NUTTI et al., 2012), milho, batata-doce e aboboraessas variedades são trabalhadas por melhoristas(WATANABE et al., 2006) que cruzam materiais de mesma espécie obtendo assim cultivares com teores elevados de ferro, zinco e pró-vitamina A (NUTTI et al., 2012).

A batata-doce apresenta grande importância na dieta de indivíduos com restrição alimentar, a biofortificação da mesma, agrega qualidade a nutrição dessa população (MELO et al., 2011). A cultivar Beauregard é a que possui melhor valores nutricionais entre as variedades de batatas-doces cultivadas no Brasil, apresentando em media de $115 \mathrm{mg} / \mathrm{kg}$ de betacaroteno, em contraste com $\pm 10 \mathrm{mg} / \mathrm{kg}$ de outras cultivares (SILVA et al., 2010). As raízes dos genótipos biofortificados são mais eficientes em absorver os micronutrientes do solo e mais efetivas em termos de penetração no perfil do solo, tornando os mais tolerantes às doenças na fase inicial de e mais econômicas na utilização de fertilizantes (BOUIS et al., 2000).

Considera-se a ingestão diária recomendada para adultos é de $600 \mathrm{mcg}$ de vitamina A (ANVISA, 2005). O consumo de 25 a $50 \mathrm{~g}$ de batata-doce Beauregard é capaz de suprir as necessidades diárias de pró-vitamina $A$, de um indivíduo adulto e saudável(BUSO et al., 2010). Na tabela americana USDA considera que $100 \mathrm{~g}$ de batata-doce contem 14.187 mcgde vitamina $A$, sendo assim seriam necessários o consumo de ao menos $42 \mathrm{~g}$ de batata-doce convencional, ressalta-se que esses valores podem sofrer alteração, devido a cultivar em questão.

Batata biofortificada pode suprir a necessidade diária de Vitamina A do que as tradicionais, onde é muito importante para população e principalmente as crianças para prevenir distúrbios onde auxilia no crescimento e fortalecimento, ajuda no combate aos radicais livres que aceleram no envelhecimento ocasionando diversas doenças (FERNANDES., et al.,2014).

Biofortificadas produtos agrícolas mais nutritivos, onde torna-se capazes de suprir as necessidades nutricionais dos seres humanos. Onde EMBRAPA tem diversos parceiros como principal alvo suprimento de micronutriente ferro, zinco e pró vitamina $A$ (MELO.,et al,2011).

São recomendadas para atacar a raiz do problema da desnutrição cientificamente viável efetivas em termos de custo, essencial para famílias carentes melhorem de forma sustentável sua nutrição e saúde. (CARVALHO., etal.,2012)

No mundo os biofortificados conhecidos por matar a fome oculto, também conhecida por deficiência de micronutrientes, reduzindo até capacidade de trabalho, distúrbios imunológicos e demais doenças que podem levar até a morte(LOUREIRO.,et al.,2018). 


\section{7. ÍNDICE GLICÊMICO E SUA IMPLICAÇÃO}

Os carboidratos presentes nas dietas estão em grande variedade nos alimentos de origem vegetal, as diferenças nos tipos de carboidratos como na composição do vegetal, tem tido ênfase para a caracterização dos seus efeitos sobre o controle da glicemia (NASCIMENTO, 2012).

O controle da glicemia é obtido por meio do Índice Glicêmico, que é caracterizado por representar a qualidade de uma determinada quantidade carboidrato disponível de um determinado alimento, onde esta quantidade é fixa. (SBD, 2006/2007ª). E também pela A carga glicêmica que se define como um produto do Índice Glicêmico, como também da quantidade de carboidrato ingerido (LOTTENBERG, 2008).

Para a diminuição da necessidade de insulina, colesterol e triglicérides, a adequação de um plano alimentar apropriado pode reduzir o Índice Glicêmico e Carga glicêmica, à essa resposta da diminuição pode-se destacar a redução de riscos de doenças cardiovasculares e diabetes (NASCIMENTO, 2012).

$\mathrm{Na}$ Tabela 6 está sendo demonstrados os dados do diferente índice glicêmico com suas classificações onde são encontrados nos alimentos, já na tabela 7 três tipos de tubérculos raízes com a demonstração da variação de alto, médio e baixo índice glicêmico.

Tabela 6. Valores para a classificação dos alimentos de acordo com o índice glicêmico e a carga glicêmica

\begin{tabular}{ccc}
\hline Classificação & IG do alimento & CG do alimento $(\mathrm{g})$ \\
\hline Baixo & $\leq 55$ & $\leq 10$ \\
Médio & 56 a 69 & 11 a 19 \\
Alta & $\geq 70$ & $\geq 20$ \\
\hline
\end{tabular}

Tabela 7. Apresentação de valores de exemplos de tubérculos com classificações distintas

$\begin{array}{cccc}\text { Alimentos } & \text { Classificação } & \text { Índice glicêmico } & \text { Carga Glicêmica } \\ \text { Batata doce } & \text { Baixo } & 54 & 17 \\ \text { Beterraba } & \text { Moderado } & 64 & 5 \\ \text { Mandioca } & \text { Alto } & 97 & 12\end{array}$

\section{PROCESSAMENTO E DESENVOLVIMENTO DE NOVOS PRODUTOS}

\subsection{Utilização}

De acordo com (SOUSA 1989) a alimentação humana, são utilizadas as raízes cozidas e assadas. As cultivares de polpa roxa, branca e creme são utilizadas no preparo de doces. E os brotos da batata doce são usadas em decoração e acompanhamento de pratos frios sendo ricos em vitamina A e B2. (SOUSA, et al 1989). Podem ainda ser usadas desidratadas na forma de farinha, à semelhança da farinha de mandioca.

A batata-doce também é de uso industrial, pode ser extraído amido de alta quantidade, empregado na indústria de tecidos, papel, cosméticos, preparação de adesivos e glucose, e na manufatura de alimentos industrializados. (SOARES, et al 2014) 
Outro destino da produção é a alimentação animal. Tanto as ramas quanto as raízes podem ser fornecidas frescas, principalmente para os animais ruminantes, mas as folhas e brotos são também consumidas por aves e peixes (LOPES, el al 1991).

\subsection{Produto Inovador}

A necessidade de produção em larga escala de embalagens duráveis, para utilização diária no mercado fez com que os plásticos assumissem um papel de destaque na produção (SOARES el al 2017). Neste cenário atual houve grande interesse na pesquisa e desenvolvimento de materiais de embalagem biodegradáveis com intuito de diminuir o acúmulo de resíduosplásticos no meio ambiente (SILVA, et al 2017).

Diante disto, buscaram desenvolver promover a síntese e caracterização de biofilmes ecológicos elaborados a partir do amido de batata doce e da crueira de mandioca (SOARES et al 2017). A aplicação do amido na confecção de biofilmes se baseia nas propriedades químicas, físicas e funcionais da amilose para formar géis e na sua capacidade para formar filmes (MACHADO, et al 2013).

A partir da polpa da batata doce roxa, Ipomoea foi desenvolvido corantes visando seu emprego como aditivo corante em alimentos. Os produtos corantes resultaram da solubilização do amido, constituinte principal da batata doce, que se atingiu por meio de hidrólise acida com ácidos minerais, como os ácidos clorídrico ou sulfúrico, ou por meio de hidrólises enzimáticas (CASCON, et al 1984).

\section{CONSIDERAÇÕES FINAIS}

A Batata Doce é uma planta rústica, é possível encontrar grande variedade de cultivares onde as raízes variam de tamanho, coloração, e também as biofortificadas.

Tem grande aceitação na população devido a suas características nutricionais, e versatilidade na produção de novos produtos.

Apresenta em sua composição nutricional alta concentração de carboidratos , compostos bioativos como flavonoides, carotenoides, antocianinas, vitamina C também é rica em fibras, muito utilizada como um alimento funcional sendo aliada em algumas patologias pois demonstra baixo índice glicêmico.

As biofortificadas são uma estratégia no combate da desnutrição visto que é enriquecida em carotenoides, é uma alternativa efetiva e sustentável, um único alimento podendo suprir algumas recomendação diárias.

Além do seu uso culinário ela tem sido explorada na indústria no desenvolvimento de produtos inovadores, como o uso do amido na produção de biofilme, e desenvolvendo produtos através das farinhas enriquecidas, na elaboração de cookies e bolos, preservando seus nutrientes.

\section{REFERENCIAS}

ALVES, E J e colab. Tratos culturais e colheita. BORGES, AL; SOUZA, LS O cultivo da bananeira. Cruz das Almas: Embrapa Mandioca e Fruticultura, p. 32-44, 2004.

ANVISA. RESOLUÇÃO DE DIRETORIA COLEGIADA - RDC №. 269, DE 22 DE SETEMBRO DE 2005. 2005.

Batista Filho M \& Rissin A (1993) A TRANSIÇÃo NUTRICIONAL NO BRASIL: 
TENDÊNCIAS REGIONAIS E TEMPORAIS.Caderno de Saúde Pública

BOUIS H. ENRICHMENT OF FOOD STAPLES THROUGH PLANT BREEDING: A NEW STRATEGY FOR FIGHTING MICRONUTRIENT MALNUTRITION.Nutr Rev.1996 May;54(5):131-7.

CASCON S. Corantes de batata doce roxa para uso em alimentos. Rio de Janeiro, 1984.

CURADO, Marília Regini Nutti; Edson Watanabe; José Luiz Viana de Carvalho; Soraya Pereira da Silva; Semiramis Rabelo Ramalho Ramos; Péricles de Carvalho Ferreira Neves; Maria José Del Peloso; Maurisrael de Moura Rocha; Vanderlei da Silva Santos; Robert Eugene Sch. Biofortificação de alimentos para combater a desnutrição no Brasil. Development, p. 8469-8469, 2010.

DA SILVA, Giovani Olegario e colab. Desempenho de cultivares de batata-doce para caracteres relacionados com o rendimento de raiz. Revista Ceres, v. 62, n. 4, p. 379-383, 2015.

ERPEN, Lígia e colab. Tuberização e produtividade de batata-doce em função de datas de plantio em clima subtropical. Bragantia, v. 72, n. 4, p. 396-402, 2013.

GINTING, E.: Carotenoid extraction of Orange-fleshed sweet potato and its application as natural food colorant. Journal Teknology dan Industri Pangan, v. 24, n. 1, 2013.

GUSSO, MATTANNA, RICHARDS. Yacon: beneficios a saúde e aplicaçoes tecnológicas. Ciencia Rural, Santa Maria, 2014.

GUERRA, Miguel Pedro e TORRES, Antônio Carlos. Indução de embriogênese somática em genótipos de batata-doce. n. 1962, p. 79-83, 2006.

GUIA ALIMENTAR, 2014. Guia Alimentar para a População Brasileira Guia Alimentar para a População Brasileira. [S.I: s.n.], 2014. v. 2.

HARVEST PLUS (2006). DESENVOLVENDO PRODUTOS AGRÍCOLAS MAIS NUTRITIVOS.

LEITE, Cláudio Eduardo Cartabiano. NOVAS CULTIVARES DE BATATAS-DOCES (Ipomoea batatas L. Lam.): POTENCIAL NUTRICIONAL, COMPOSIÇÃO DE BIOATIVOS, PROPRIEDADES ANTIOXIDANTES E ANÁLISE DIGITAL DE IMAGEM. p. 1-201, 2017.

LOPES, C. A.; SILVA J. B. C. Efeito da posição da rama-semente e do controle químico na manifestação do mal-do-pé da batata-doce. Horticultura Brasileira, Brasília, DF, v. 9, p. 43, 1991 
LÓPEZ O.P.; JIMÉNEZ A.R.; VARGAS F.D. et al. Natural pigments: carotenoids, anthocyanins, and betalains - characteristics, biosynthesis, processing, and stability.Critical Reviews Food Science Nutrition, v.40, n.3, p.173-289, 2000.

LOTTENBERG, Ana.M.P. Características da Dieta nas Diferentes Fases da Evolução do Diabetes Melito Tipo 1. Disciplina de Endocrinologia do Hospital das Clínicas da Faculdade de Medicina da Universidade de São Paulo (FMUSP), SP, Brasil. Arq Bras Endrocrinol Metab., 2008;52/2.

MACHADO TR. Elaboração e avaliação de filmes biodegradáveis a base de amido de mandioca e bagaço de cevada. Anápolis: Universidade estadual do Goiás; 2013.

MELO, Werito Fernandes De e colab. BIOFORTIFICAÇÃO NO BRASIL (2011 0

BioFORT): AVALIAÇÃO PRELIMINAR DE CLONES DE BATATA-DOCE RICOS EM BETACAROTENO EMM DUAS ÉPOCAS. n. 1, p. 2675-2680, 2011.

NASCIMENTO, B. V. Emprego do índice glicêmico e carga glicêmica dos alimentos: uma alternativa nas dietas de pacientes com doenças crônicas? Rio de janeiro, 2012.

NORONHA, Luis Antônio de Castro; Andréa Denise Hildebrandt. Cultivo da batatadoce: principais utilidades. 2018.

NUTTI, João Bosco Carvalho da Silva;Werito Fernandes de Meio; José Amauri Buso; Marllia Regini. Beauregard. 2010.

NUTTI, José Luiz Viana de Carvalho; Marília Regini. BIOFORTIFICAÇÃO DE PRODUTOS AGRíCOLAS PARA NUTRIÇÃO HUMANA. p. 1-50, 2012.

OMS. Healthy diet. n. May, p. 1-6, 2015.

RÓS, Amarílis Beraldo e TAVARES FILHO, João e BARBOSA, Graziela Moraes de Cesare. Produtividade da cultura da batata-doce em diferentes sistemas de preparo do solo. Bragantia, v. 72, n. 2, p. 140-145, 2013.

SEVERO, F. N. Santos; L. Nachtigal; A. F. S. Mello; T. Samborski; A. A. Michelotti; J. Elaboração de doces utilizando batata-doce biofortificada cv. beauregard. n. 55, p. 1-7, 2018.

SILVA., João Eustácio Cabral de Miranda; Felix Humberto França; Osmar Alves Carrijo; Antonio Fancisco Souza; Welington Pereira; Carlos Alberto Lopes; João Bosco C. Coleção plantar: batata doce. [S.I: s.n.], 1995.

SILVA, Giovani Olegario Da e colab. Desempenho de cultivares de batata-doce para caracteres relacionados com o rendimento de raiz TT - Performance of root yield traits in sweet potato cultivars. Revista Ceres, v. 62, n. 4, p. 379-383, 2015. 
SANTOS, NOVELLO. Desenvolvimento de cookies adicionados de farinha de Yacon (Smallanthus sonchifolius) caracterizacao química e aceitabilidade sensorial entre portadores de Diabetes Mellitus.Revista Instituto Adolfo Lutz. Janeiro, 2014.

SILVA, J.B.C. Da e colab. Cartilha-Biofortificacao-Batata-Doce.pdf. . [S.I: s.n.]. , 2010.

SILVA, E. Produção e caracterização de filmes biodegradáveis de amido de pinhão Trabalho de diplomação. Porto Alegre: Universidade Federal do Rio Grande do Sul; 2011.

SOARES I.F.O, FAKHOURI F.M, GIRALDI A.L.F.M, BUONTEMPO R.C. Síntese e caracterização de biofilme de amido plastificado com glicerol ou triacetina. 2014 Sociedade Brasileira de Diabetes (SBD). Sintomas de Diabetes, complicações crônicas. São Paulo, SP.

SOUZA, Antonio Francisco e colab. Batata-doce(Ipomoea batatas(L.) LAM). Embrapa Hortaliças-Circular Técnica (INFOTECA-E), n. 0102-6534, p. 19, 1989.

WATANABE, Marilia Regini Nutti; Jose Luiz Viana de Carvalho; Edson. A Biofortificação como ferramenta para combater a deficiências em micronutrientes. [S.I: s.n.]. , 2006. 